www.jmscr.igmpublication.org

Impact Factor 5.84

Index Copernicus Value: 83.27

ISSN (e)-2347-176x ISSN (p) 2455-0450

crossref DOI:_https://dx.doi.org/10.18535/jmscr/v5i7.17

Journal Of Medical Science And Clinical Research

\title{
Physiological and Pathological Ocular Conditions in Pregnancy
}

\author{
Authors \\ Jitendra Kumar', Vijay Pratap Singh ${ }^{2}$, Prachi Agarwal ${ }^{3}$, Amit Verma ${ }^{4}$ \\ ${ }^{1}$ Associate Professor, Dept of Ophthalmology, Maharani Laxmi Bai Medical College, Jhansi, UP, India \\ ${ }^{2}$ Junior Resident, Dept of Ophthalmology, Maharani Laxmi Bai Medical College, Jhansi, UP, India \\ ${ }^{3}$ Junior Resident, Dept of Obstetrics\& Gynaecology, Maharani Laxmi Bai Medical College, Jhansi, UP, \\ India \\ ${ }^{4}$ Junior Resident, Dept of Ophthalmology, Maharani Laxmi Bai Medical College, Jhansi, UP, India
}

\section{Abstract}

Pregnancy is often associated with ocular changes which may be more commonly transient and occasionally permanent. The ocular effects of pregnancy may be physiological or pathological or may be modifications of pre-existing conditions. The physiological changes affect multiple organ systems including the visual system. Although ocular changes are common in pregnancy, many are mild, temporary, and require little to no treatment. However, it is important to recognize that serious ophthalmic pathology can occur which requires immediate medical intervention. The various effects of pregnancy on the eye will be reviewed throughout this article.

Keywords: Anti-phospholipid Syndrome (APS), Central Serous Chorioretinopathy (CSCR), Diabetic Retinopathy(DR), Disseminated Intravascular Coagulation (DIC), Optical Coherence Tomography (OCT).
\end{abstract}

\section{Introduction}

Pregnancy causes major changes in all systems of the body. Physiological changes protect the fetus, support development, and also prepare the mother for birth. These changes affect the cardiovascular, renal, pulmonary, endocrine, metabolic, hematologic and visual systems. ${ }^{[1]}$ For example, in early pregnancy cardiac output and blood volume increase by $30-50 \%$. Decreased fibrinolytic activity and increases in plasminogen, fibrinogen and factors I, V, VII, IX and $\mathrm{X}$ result in a predisposition toward coagulation. Toward the end of pregnancy, extracellular d increases by up to two liters. Cellular immunity decreases, but there are no changes in immunoglobins. ${ }^{[2]}$
The ophthalmic complications are divided into physiologic and pathologic changes. Pathologic changes in pregnancy are further segregated into three categories including: first time ocular pathology during pregnancy, modification of an existing ocular pathology, and ocular complications of systemic disease ${ }^{[3] \text {. }}$

Although ocular complications are common in pregnancy, many are mild, temporary, and require little to no treatment. However, it is important to recognize that serious ophthalmic pathology can occur which requires immediate medical intervention. This article is a review of the pathological and physiological changes which occur within the parturient. 


\section{Physiological Ocular Changes}

Pigmentation of the eyelids and around the eye is commonly increased during gestation. Known as chloasma or melasma, the increased pigmentation usually is reversible and regresses after delivery. Darkening of the face during pregnancy is referred to as pregnancy mask, cloasma or melasma and develops through increased estrogen, progesterone and melanocyte-stimulating hormone. ${ }^{[4]}$

Pregnancy can also affect tear physiology and lead to dry eye. This may be attributable to increased immune reaction in the lacrimal duct cells and the direct destruction of acinar cells by prolactin, transforming growth factor beta-1 and epidermal growth factor. Dryness can be further increased by dehydration resulting from nausea and vomiting and the use of anti-nausea medications. ${ }^{[5]}$ Pregnancy is also known to alter corneal thickness and curvature ${ }^{[6-8]}$. Due to these physiological changes, it is better to delay refractive surgery during pregnancy. Refractive corneal procedures such as LASIK are contraindicated and should be postponed until refractive changes stabilize in the postpartum. Also, dry eye and decreased corneal sensation could result in significant postoperative complications such as poor wound healing and corneal melt ${ }^{[9]}$. It is even recommended to delay changing prescription glasses as new lenses are not likely to be suitable once physiological changes resolve in the postpartum. Intraocular pressure can also be affected. It can be significantly decreased during pregnancy ${ }^{[10-13]}$

\section{Pathological Ocular Changes}

Effect of Pregnancy on Preexisting Ocular Disorders

Pregnancy has an effect on preexisting ocular conditions such as Diabetic retinopathy, Glaucoma, intracerebral tumors, uveitis, multiple sclerosis, and other inflammatory conditions. Thus it is important to understand how these diseases change during gestation.

Diabetic Retinopathy: With the rise of the obesity epidemic, the number of woman with diabetes during pregnancy has increased over the past decades ${ }^{[14] .}$ Pregnancy itself is a major risk factor for the progression and development of diabetic retinopathy. In particular, the progression of diabetic retinopathy is strongly influenced by a variety of factors including: the duration of diabetes, glycemic control, severity of retinopathy prior to conception, and the presence of hypertension. However, gestational diabetes is not linked with diabetic changes within the eye ${ }^{[15]}$. The duration of diabetes increases the risk of retinal changes. In other words, the longer the patient has diabetes, the greater the risk for diabetic retinal disease. Thus, it is recommended that women plan their conception during the third decade. Studies have shown that diabetic complications during pregnancy increase dramatically with maternal age . Poor glycemic control also affects the progression of diabetic retinopathy. Higher levels of $\mathrm{HbA} 1 \mathrm{C}$ at conception are linked with higher risk of retinopathy. Thus, tight glycemic control should be attained before conception ${ }^{[15-17] .}$

Glaucoma: Glaucoma is another preexisting disease modified by pregnancy. As mentioned earlier, intraocular pressure is decreased during pregnancy [9-13]. Intraocular pressure decreases during the second trimester and continues to decrease with the advancing pregnancy [13]. In most cases, lower intraocular pressure means glaucoma improves with pregnancy [18-19]. However, peripheral vision is also affected during pregnancy. During the last trimester of pregnancy, mean threshold sensitivity of the entire central and regional visual field increases ${ }^{[19]}$.

Pituitary adenoma: Pregnancy may also affect the growth of pituitary adenomas and microadenomas. Pregnancy stimulates the growth of the prolactin secreting cells within the pituitary, thus increasing the size of the gland ${ }^{[20]}$. However, most microadenomas or pituitary adenomas are asymptomatic prior to and during pregnancy. However some individuals may become symptomatic once the adenoma progresses to a certain size. The patient may complain of mass-effect symptoms including headache, bitemporal field defects, decrease in 
visual acuity, and diplopia. Treatment for symptomatic patients includes surgery, radiation, bromocriptine, and corticosteroids depending if the mass is an adenoma or prolactinoma [21]. Treatment is effective and has no interactions on the infant. After pregnancy, pituitary adenomas may regress in size, resulting in no long term visual deficits. It is recommended that parturients with pituitary adenomas and microadenomas have monthly ophthalmic examinations with visual field assessment to rule out enlargement.

Meningioma: Growth of meningiomas may also be affected by gestation, growing rapidly during pregnancy. Parturients become symptomatic once the tumor reaches a certain threshold, complaining of decreased vision and visual field loss [22]. Treatment for symptomatic patients is usual surgical [23]. However, mild symptoms can be observed with treatments occurring in the postpartum.

Inflammatory conditions: Inflammatory disorders such as rheumatoid arthritis, sarcoidosis, and spondyloarthropathy have both systemic and ocular manifestations which notably decrease during pregnancy ${ }^{[24]}$. The decreased symptomatic presentation of these pathologies may be due to rise of corticosteroids found in pregnancy. Symptoms of these inflammatory diseases are usually exacerbated in the postpartum ${ }^{[25] \text {. }}$

Toxoplasmosis: Toxoplasmosis may also be affected by pregnancy. There have been known cases of reactivation of ocular toxoplasmosis within the parturient during pregnancy. The fetus's risk for contacting congenital toxoplasmosis is extremely low. Treatment involves spiramycin which has been documented to be safe in pregnancy ${ }^{[26] .}$

Ophthalmic medications: There is much uncertainty regarding the safety of using ophthalmic medications during pregnancy and breastfeeding. Most drug information is derived from animal experimentation due to the lack of clinical trials on pregnant women. Although animal experimentation provides a good foundation for drug safety, findings cannot necessarily be extrapolated to humans. Thus, when any ophthalmic medication is given topically in pregnant or breastfeeding individuals it is recommended that two steps be performed. First, the lowest effective topical dose must be given. Secondly, systemic absorption should be minimized by using nasolacrimal compression and wiping excess medication from the face. Also since topical medication drains into the nasolacrimal ducts with eye blinking, prolonged closure of the eyelids for 1 to 2 minutes will decrease drainage and systemic absorption ${ }^{\text {[27]. }}$

Ocular pathology initially presenting in pregnancy Central Serous Chorioretinopathy: Central Serous Chorioretinopathy (CSCR) can occur during pregnancy with increased frequency during the third trimester. Patients present with visual loss, central scotomas, metamorphopsia, delayed retinal recovery following photostress, loss of color saturation, and contrast sensitivity. CSCR may present with a serous subretinal exudation with an underlying retinal pigment epithelium detachment. The exact mechanism is unknown but is hypothesized to include abnormal ion transport across the retinal pigment epithelium and focal choroidal vasculopathy. Optical Coherence Tomography (OCT) is the diagnostic investigation of choice. Central Serous Chorioretinopathy is reversible after several months of postpartum ${ }^{\text {[28]. }}$

Vascular Occlusive Diseases: This group of conditions includes retinal artery occlusions, retinal vein occlusions, disseminated intravascular coagulopathy (DIC), thrombotic thrombocytopenic purpura (TTP), antiphospho lipid antibody syndrome (APS), amniotic fluid embolism, and cerebral venous thrombosis. As indicated previously, hypercoagul ability occurs in pregnancy. Pregnancy related central and branch retinal artery occlusion has rarely been reported. Retinal vein occlusions are rarer than arterial occlusions. DIC may develop in pregnancies with 
complications such as abruptio placenta, preeclampsia/eclampsia, complicated birth, amniotic fluid embolism, intrauterine infection and intrauterine death. DIC is a serious condition characterized by diffuse small vessel thrombosis and subsequent hemorrhage and tissue necrosis ${ }^{[29,30]}$ In the eye, the choroid layer is most affected; thrombosis in the choriocapillaris disrupting the retinal pigment epithelium may cause serous retinal detachment. Ocular symptoms improve with DIC treatment, though mild pigmentary changes may persist. ${ }^{[31]}$

HELLP syndrome is a condition characterized by hemolysis, elevated liver enzymes and lowered thrombocyte count; it is typically seen in preeclamptic patients and generally appears with DIC. Serous retinal detachment, vitreous hemorrhage, central retinal vein occlusion and Purtscher-like retinopathy have been reported in these patients ${ }^{\text {. } 32,33,34,]}$

TTP is a rare disease, and ocular changes are observed in $10 \%$ of TTP patients. Fundus changes occur in the form of serous retinal detachment, retinal hemorrhage, exudates and narrowing of the arterioles. Involvement of the vessels supplying the optic nerve may lead to optic atrophy. Anisocoria, subconjunctival hemorrhage, scintillating scotoma, extraocular muscle paresis and homonymous hemianopia may occur ${ }^{[35]}$

APS is a thrombophilic condition; patients are predisposed to arterial and venous thrombosis and antiphospho lipid antibodyrelated pregnancy morbidity is observed. Anterior segment findings accompanying this syndrome may include conjunctival telangiectasia and micro aneurysms, episcleritis, limbal or filamentous keratitis, and iritis. Posterior segment findings may include vitreitis, retinal detachment, posterior scleritis, central retinal vein occlusion, retinal vein branch occlusion, cilioretinal artery occlusion, increased venous tortuosity, retinal hemorrhage, and soft exudates. Furthermore, vascular thrombosis may develop in the choroid, optic nerve, visual pathways and ocular motor nerves ${ }^{[36,37]}$

\section{Conclusion}

Most of the ocular changes in pregnancy are harmless. Some changes, however, are serious, such as retinal effects of hypertension, which can be a sign of pre-eclampsia and eclampsia or preexisting ocular diseases. Ocular changes may give rise to uncertainty about the administration of ophthalmological drugs or the optimal method of childbirth. Certain ocular changes, whether physiological or pathological, may be increased during pregnancy. Many ocular changes are mild, temporary, and require little to no treatment, all ocular symptoms in pregnancy requires ophthalmologic examination is necessary and monitoring the disease.

\section{References}

1. Carlin A, Alfirevic Z. Physiological changes of pregnancy and monitoring. Best Pract Res Clin Obstet Gynaecol. 2008;22:801-823

2. Thornburg KL, Jacobson SL, Giraud GD, Morton MJ. Hemodynamic changes in pregnancy. Semin Perinatol. 2000;24:1114.

3. Pilas-Pomykalska M, Czajkowskii J, Oszukowski P (2005) [Ocular changes during pregnancy]. Ginekol Pol 76(8): 655-660.

4. Jadotte YT, Schwartz RA. Melasma: insights and perspectives. Acta Dermatovenerol Croat. 2010;18:124-129

5. Schlehter JE, Pidgeon M, Chang D, Fong YC, Trousdale MD, Chang N. Potential role of disrupted lacrimal acinar cells in dry eye during pregnancy. Adv Exp Med Biol. 2002;506:153-157.

6. Weinreb RN, Lu A, Beeson C (1988) Maternal corneal thickness during pregnancy. Am J Ophthalmol 105(3): 258260.

7. Park SB, Lindahl KJ, Temnycky GO, Aquavella JV (1992) The effect of pregnancy on corneal curvature. CLAO J 18(4): 256-269. 
8. Fatt I, Harris MG (1973) Refractive index of the cornea as a function of its thickness. Am J Optom Arch Am Acad Optom 50(5): 383-386.

9. Samra KA (2013) The eye and visual system in pregnancy, what to expect? An in-depth review. Oman J Ophthalmol 6(2): 87-91.

10. Sunness JS (1988) The pregnant woman's eye. Surv Ophthalmol 32(4): 219-238.

11. Akar Y, Yucel I, Akar ME, Zorlu G, Ari ES (2005) Effect of pregnancy on intraobserver and intertechnique agreement in intraocular pressure measurements. Ophthalmologica 219(1): 36-42.

12. Sen E, Onaran Y, Nalcacioglu-Yuksekkaya P, Elgin U, Ozturk F (2014) Corneal biomechanical parameters during pregnancy. Eur J Ophthalmol 24(3): 314-319.

13. Ebeigbe JA, Ebeigbe PN, Ighoroje A (2012) Ocular changes in pregnant Nigerian women. Niger J Clin Pract 15(3): 298-301.

14. Ali S, Dornhorst A (2011) Diabetes in pregnancy: health risks and management. Postgrad Med J 87(1028): 417-427.

15. Sheth BP (2008) Does pregnancy accelerate the rate of progression of diabetic retinopathy? an update. Curr Diab Rep 8(4): 270-273.

16. (1979) The Diabetic Retinopathy Study Research Group, Four risk factors for severe visual loss in diabetic retinopathy. The third report from the Diabetic Retinopathy Study. Arch Ophthalmol 97(4): 654-655.

17. Horvat M, Maclean H, Goldberg L, Crock GW (1980) Diabetic retinopathy in pregnancy: a 12-year prospective survey. Br J Ophthalmol 64(6): 398-403.

18. Qureshi IA, Xi XR, Wu XD (1996) Intraocular pressure trends in pregnancy and in the third trimester hypertensive patients. Acta Obstet Gynecol Scand 75(9): 816-819.
19. Efe YK, Ugurbas SC, Alpay A, Ugurbas SH (2012) The course of cornealand intraocular pressure changes during pregnancy. Can J Ophthalmol 47(2): 150154.

20. Molitch ME (2003) Pituitary tumors and pregnancy. Growth Horm IGF Res 13 Suppl A: S38-S44.

21. Imran SA, Ur E, Clarke DB (2007) Managing prolactin-secreting adenomas during pregnancy. Can Fam Physician 53(4): 653-658.

22. Wan WL, Geller JL, Feldon SE, Sadun AA (1990) Visual loss caused by rapidly progressive intracranial meningiomas during pregnancy. Ophthalmology 97(1): 18-21.

23. Kanaan I, Jallu A, Kanaan H (2003) Management Strategy for Meningioma in Pregnancy: A Clinical Study. Skull Base 13(4): 197-203.

24. Kump LI, Cervantes-Castañeda RA, Androudi SN, Foster CS, Christen WG (2006) Patterns of exacerbations of chronic non-infectious uveitis in pregnancy and puerperium. Ocul Immunol Inflamm 14(2): 99-104.

25. Mor G, Cardenas I, Abrahams V, Guller S (2011) Inflammation and pregnancy: the role of the immune system at the implantation site. Ann N Y Acad Sci 1221: 80-87.

26. Bonfioli AA, Orefice F (2005) Toxoplasmosis. Semin Ophthalmol 20(3): 129-141.

27. Chung CY, Kwok AK (2004) Chung KL Use of ophthalmic medications during pregnancy. Hong Kong Med J 10(3): 191195

28. Sunness JS, Haller JA, Fine SL (1993) Central serous chorioretinopathy and pregnancy. Arch Ophthalmol 111(3): 360364

29. Patchett RB, Wilson WB, Ellis PP. Ophthalmic complications with dissemi- 
nated intravascular coagulation. $\mathrm{Br} \quad \mathrm{J}$ Ophthalmol. 1988;72:377-379.

30. Hoines J, Buettner H. Ocular complications of disseminated intravascular coagulation (DIC) in abruptio placentae. Retina. 1989;9:105-109.

31. Montagnana M, Franchi M, Danese E, Gotsch F, Guidi GC. Disseminated intravascular coagulation in obstetric and gynecologic disorders. Semin Thromb Hemost. 2010;36:404-418.

32. Yilmaz A, Pata Ö, Öz Ö, Yildırım Ö, Dilek S. Preeklampside iki taraflı seröz retina dekolman1. Ret-Vit. 2005;13:307310.

33. Taşkapili M, Kocabora S, Gülkilik G. Unusual ocular complications of the HELLP syndrome:persistent macular elevationand localized tractional retinal detachment. Ann Ophthalmol. (Skokie) 2007;39:261-263.

34. Gültan E. Gebelikte karşılaşılan göz hastalıkları. Tibbi Retina. Türk Oftalmoloji Derneği Eğitim Yayınları. 2009;10:211-218.

35. Percival SP. Ocular findings in thrombotic thrombocytopenic purpura (Moschcowitz's disease). Br J Ophthalmol. 1970;54:73-78.

36. Durrani OM, Gordon C, Murray PI. Primary anti-phospholipid antibody syndrome (APS)-current concepts. Surv Ophthalmol. 2002;47:215-238.

37. Tsironi E, Gatselis N, Kotoula MG, Zachou K, Pefkianaki M, Zacharaki F, Chatzoulis DZ, Dalekos GN. Ocular disorders as the prevailing manifestations of antiphospholipid syndrome: a case series. Cases J. 2009;2:159. 